\title{
Síntese da migração em Goiás e no Distrito Federal nas últimas décadas
}

\author{
Ernesto Friedrich de Lima Amaral* \\ ROBERTO DO NasCimento RODRIGUES* \\ Moema Gonçalves Bueno Figoli**
}

\begin{abstract}
R esumo: O artigo trata dos movimentos migratórios em Goiás e no Distrito Federal, sintetizando o panorama que se forma nas áreas de maior atração de contingentes populacionais na Região Centro-Ceste, as microrregiões de Goiânia e Entomo do Distrito Federal. De início, localiza nos anos setenta um redirecionamento migratório na região, decorrente do desenvolvimento db capital na agriaultura, que mecaniza lavouras e altera as relaçães sociais de produção. O predomínio no períodb anterior, da absorção de excedentes populacionais de outras regiões, dá lugar, nos anos seguintes, a um maior fluxo de trabalhadores em direção às cidades. Na última parte, os autores traçam um perfil da migração nas regiões estudadas, recorrendb a classificações da literatura para fluxos migratórios e a redefinições do território provocadas pela modemização agrícola. Também sustentam o estudb, técricas de análise de migração e comparaçães das tendências nas duas áreas principais com os dados das 16 microrregiões de Goiás.
\end{abstract}

Palavr as-chave: migração; Região Centro-Ceste; modemização.

Com o objetivo de compreender as especificidades da migração em Goiás e no Distrito Federal, é importante, primeiro, resumir o processo de inserção de Goiás nos cenários socioeconômico e político nacionais e, depois, sintetizar o panorama da migração nessa região nas últimas décadas.

1 Origens da inserção de Goiás nos cenários socioeconômico e político nacionais

A nova elite dominante da política brasileira, surgida com a Revolução de 1930, era formada

\footnotetext{
* Mestre em Demografia pelo Centro de Desenvolvimento e Planejamento Regional (Cedeplar), da UFMG, e doutorando em Sociologia na Universidade do Texas.

** Doutor em Demografia e professor titular do Cedeplar/ UFM G.

*** Doutora em Demografia e professora adjunta do Cedeplar/U FM G.
}

por militares, técnicos diplomados e jovens políticos e teve como principais características: a centralização das decisões econômicas e políticas no âmbito do Executivo nacional; a promoção da industrialização de forma mais intensiva; a adoção de políticas que assegurassem direitos trabal histas, e a soberania dada às Forças A rmadas, com o objetivo de promover a ordem e o progresso. Os empresários industriais passaram a fazer parte do governo, porque correspondiam aos interesses da nova elite, já que se encaixavam nos planos de implementação de indústrias no país (Fausto, 1995).

Como assegura Borges (2000), o período compreendido entre 1930 e 1960 foi caracterizado pela industrial ização do Sudeste, assegurando o desenvolvimento de uma economia nacional que abrangeu economias agrárias regionais, anteriormente pouco exploradas. 
N esse contexto, insere-se a economia de G oiás, que estava nos planos de expansão da industrialização e do desenvolvimento nacionais da época. 0 sistema econômico brasileiro estabelecia-se com base em um padrão de acumulação de capital, caracterizado por um desenvolvimento de atividades industriais e agrícolas, que se inter-relacionavam num processo em que 0 setor industrial estabelecia os limites de desenvolvimento de acumulação de capital no campo. Porém, mesmo com um processo de automação e modernização da agropecuária, havia uma permanência de formas nãocapitalistas de produção e uma repartição das terras em grandes latifúndios, concentrados nas mãos de poucos fazendeiros.

$\mathrm{N}$ esse período, os meios de transporte e de comunicação instalados foram muito importantes para o fluxo de produtos de importação e exportação, assim como para o fluxo populacional em direção a Goiás e ao Centro-Oeste, como um todo. Essas transformações, incentivando um processo de modernização, ocorreram de uma forma lenta e desigual na região. A aprimoração das vias de transporte facilitou a expansão da fronteira econômica e demográfica, reestruturando o espaço agrário goiano. Essas realizações foram resultado das ações políticas do governo federal e do movimento do capital, com origem no Sul e Sudeste, e com destino às demais regiões do território brasileiro.

A dinâmica econômica interna de Goiás, nesse período, configura-o como um espaço primordialmente agropecuário, diretamente ligado à economia urbano-industrial do Sudeste, na medida em que os produtos primários são direcionados a esse mercado central. É importante observar que a divisão inter-regional do trabalho, entre economia urbano-industrial e economia agrária, não implica que esta fosse menos importante no processo de reprodução do capital. Pelo contrário, a modernização da produção agropecuária goiana, fornecendo produtos cada vez mais baratos aos centros urbanos, permitia um desenvolvimento conjunto com a economia industrial do país.

A inda de acordo com as argumentações de Borges (2000), constata-se que esse processo de desenvolvimento nacional, proposto após a R evolução de 1930, que tinha como um dos objetivos implementar profundas transformações no setor agrário, não al terou a estrutura latifundiária anterior. A automação e a modernização técnica do campo foram ef etivadas, mas a democratização do acesso à terra não se concretizou. Segundo esse autor, "a natureza política e ideológica do Estado oligárquico, numa nova roupagem, garantia a continuidade da velha estrutura agrária e bloqueava a ação política no sentido de transformá-la" (idem, ibidem).

Sob um ponto de vista diferente, Chaul (1997) observa que esse processo vivido por Goiás não deve ser entendido como uma simples mudança nos poderes políticos nacional e regional. 0 autor afirma que "1930 em Goiás foi muito mais do que uma simples 'al ternância deoligarquias no poder'. Significou a construção de um projeto político baseado na idealização da modernidade, com a participação relativa das camadas médias urbanas" (idem, ibidem).

De todo modo, tanto Borges (2000) como Chaul (1997), seja pelo argumento de que G oiás se inseria em um novo padrão de acumulação de capital, seja pela constatação de que o Estado passava por um processo de idealização e construção da modernidade, concordam que, após a revolução, ocorreram mudanças significativas nas configurações econômica, política e social goianas.

0 projeto político em Goiás, ao qual se refere Chaul (1997), foi coordenado pelo interventor federal Pedro Ludovico Teixeira. $\mathrm{Na}$ época de sua nomeação por G etúlio Vargas, ainda não havia um projeto de governo estabelecido, e nem mesmo uma orientação ideológica que delinearia os rumos das políticas a ser implementadas. Foram idealizadas, então, duas representações fundamentais que conduziriam à construção da modernidade em Goiás. A primeira delas seria a execução de um projeto de saneamento e de educação. Porém, em virtude da falta de recursos financeiros provenientes do governo federal, o governo estadual acabou suspendendo tal projeto sanitário. A segunda idéia era a da mudança da capital, da cidade de Goiás, para uma nova cidade que seria planejada e construída (futura Goiânia). Essa mudança da capital não era uma idéia nova, já que havia sido proposta nos séculos XVIII e XIX. 
A mudança da capital passava ao seu significado mais global: um símbolo de ascensão ao poder, uma representação do progresso, do moderno, um divisor de águas entre o velho e o novo Goiás. Assim, Pedro Ludovico resgatava as idéias de mudança da capital dos séculos XVIII e XIX e as utilizava para sua plataforma de ascensão política. (Chaul, 1997)

A lém de buscar a permanência no poder, Pedro Ludovico, ao utilizar o argumento da modernidade, para a construção da nova capital, passaria a contar com o apoio de grupos políticos do sul e sudoeste goianos, regiões mais promissoras do estado na época. Como a cidade de Goiás possuía instalações muito precárias e sua local ização não era de fácil acesso, a construção de Goiânia significaria, ainda, a dinamização do processo político-burocrático, levando G oiás a uma maior inserção no mercado nacional.

Desse modo, mesmo com recursos financeiros limitados e sofrendo oposição de grupos tradicionais dentro do estado, o governo de Pedro L udovico anunciou o processo de construção de Goiânia, em 4 de julho de 1932. A mão-de-obra teve origem, principalmente, no Rio de Janeiro, em São Paulo, M inas Gerais e na Bahia, somando cerca de quatro mil trabal hadores. Em 23 de março de 1937, foi assinado o decreto de mudança da capital. Em 10 de novembro de 1937, G etúlio Vargas decretava 0 Estado Novo, pondo fim às articulações contrárias à mudança da capital. Em julho de 1942, ocorreu a inauguração oficial de Goiânia, parte do projeto de "conquista do Oeste", implementado pelo novo governo federal.

Quanto à mudança da capital federal pelo governo de J uscelino K ubitscheck, em 1960, é importante lembrar que a construção de B rasília pode ser vista como um dos esforços mais significativos de planejamento regional real izados no país. Porém, conforme ressalta Pastore (1969), a mudança da capital nacional era algo que vinha sendo discutido há muito tempo, por governos anteriores.

A idéia de se mudar a capital do B rasil para 0 interior apareceu, pela primeira vez, em 1789, em conexão com o movimento da Inconfidência M ineira. A idéia transformou-se em artigo da constituição brasileira em 1890 e foi mantida nas constituições subseqüentes até a de 1946. Decisões concretas para a construção da cidade, entretanto, efetivaram-se em 1957, quando o plano de Lúcio Costa foi escolhido como o projeto vencedor dentre os vinte e seis concorrentes. (Idem, ibidem)

A construção de Brasília foi um empreendimento do governo federal da época com o intui to de povoar o interior do B rasil, introduzir recursos econômicos em áreas despovoadas, conquistar e desenvolver as áreas potencialmente ricas da Bacia A mazônica, introduzir e desenvolver uma sólida agricultura em Goiás, no $M$ ato $G$ rosso e $M$ aranhão, desenvolver um sistema de comunicação que contribuísse para a integração nacional e combater a inflação. A lém disso, Pastore (1969) afirma que uma série de fatores psicossociais devem ser lembrados nessa discussão, já que

a) o desenvolvimento do interior contribuiria para diminuir as desigual dades existentes entre as diferentes regiões do B rasil; b) a criação de uma nova capital seria acompanhada pela emergência de uma burocracia moderna, livre dos vícios da máquina governamental do Rio de Janeiro; c) o novo plano urbanístico concentraria as agências governamentais de modo a facilitar a comunicação e a eficiência das mesmas; d) a idéia de uma nova capital proporcionaria um novo símbolo popular para o futuro do país; e) sendo um plano ambicioso eatrevido do ponto de vista artístico e técnico, B rasília provaria ao povo brasileiro e ao mundo o que 0 Brasil é capaz de fazer; f) e, finalmente, as modernas linhas da planta física e das facilidades de habitação contribuiriam para criar uma vida 'mais democrática' tanto para os altos dirigentes do país como para os simples trabalhadores. Em suma, Brasília seria não apenas uma cidade nova mas, principalmente, um símbolo de progresso [...]. (Idem, ibidem)

Em meio a um grande debate sobre o custo e as conseqüências da construção da nova capital federal, B rasília foi inaugurada a 21 de abril de 1960, gerando um intenso movimento migratório em direção ao Planalto Central, alvo de preocupação para os próprios migrantes e para os planejadores e autoridades governamentais da época. De qual quer forma, o "Plano de M etas" do governo de J uscelino K ubitscheck, 
ao possibilitar a construção de B rasília, implementou uma idéia que vinha sendo formada há muito tempo pela sociedade brasileira.

\section{A migração no Centro-O este brasileiro}

A o analisar o processo migratório no Centro-O este, principalmente na década de 1970, Salim (1992) observa que houve uma apropriação acelerada da terra, automação e modernização técnica do campo, concentração das propriedades e dos recursos financeiros e modificação das relações sociais de produção, com o aumento das formas de trabalho assalariado no campo. Essas mudanças na estrutura fundiária levaram a uma diminuição de necessidade de mão-de-obra no campo e, conseqüentemente, a uma mobilidade ocupacional e espacial da força de trabalho. Desse modo, se o período anterior aos anos 70 ficou marcado pela absorção de excedentes populacionais de outras regiões pela agricultura regional, o período posterior caracterizou-se pelo fluxo de trabal hadores agrícolas em direção às cidades. A partir de então, a produção agrícola limitou-seà util lização da mão-de-obra regional, beneficiada pela expropriação dos pequenos proprietários e pela impossibilidade de acesso à terra pelos "sem-terra". Foi esse processo de desenvolvimento do capital na agricultura e a mudança das relações sociais de produção que geraram um excedente populacional no campo, determinando os processos migratórios no Centro-O este, nas décadas de 1970 e 1980.

Esses processos migratórios foram desagregados por Sal im (1992) em: migrações interregionais, em que os fluxos populacionais se dirigiram principal mente ao meio rural; migrações intra-regionais, que foram mais expressivas em regiões com inserção de relações capitalistas, expulsando boa parcela da população do campo; migrações interestaduais, que se caracterizaram por uma migração rural-rural em regiões de ocupação mais recente; migrações intra-estaduais, com predominância dos fluxos rural-urbano em áreas de maior desenvolvimento capitalista, e migrações intramunicipais, que se sobrepuseram aos fluxos intermunicipais e interestaduais, caracterizadas pelo redirecionamento populacional daqueles que haviam realizado migração com destino rural, aumentando a tendência de maior crescimento urbano e metropolitano.

0 redirecionamento migratório ocorreu em decorrência da crescente mecanização da atividade agrícola, da redução do espaço físico para a reprodução da pequena produção, da elevação dos custos sociais, que levaram à retração do emprego no campo e à intensificação da mobilidade da força de trabalho, enfraquecendo a atração populacional da fronteira agrícola do Centro-O este e determinando uma perda da importância dos fluxos migratórios interregionais. A ssim sendo, os fluxos migratórios intramunicipais de sentido rural-urbano e a mobilidade espacial da força de trabalho de origem rural passaram a apresentar uma maior importância na configuração populacional do Centro-O este.

A o analisar o processo de produção agropecuária no Centro-O este, M ueller, Torres \& M artine (1992) afirmam que a expansão e modernização da agricultura ocorreram conjugadas com uma redução na absorção de mão-de-obra. Dessa forma, o fato de a evolução da agricultura não ter acarretado um considerável aumento no emprego rural acabou produzindo conseqüências na evolução da população rural, mesmo não sendo um efeito de aparência imediata.

Para a realização dessa análise, os autores dividiram o território em quatro zonas: moderna, que apresenta uma agricultura consolidada e moderna; expansão, com uma agricultura desenvolvida e modernizada recentemente e centralizada na produção de soja; fronteira, caracterizada pelo baixo uso da terra para atividades de colheita e por uma produção pecuária extensiva, e residual, com uma agricultura com baixo crescimento e pequena produtividade.

A zona moderna exibe a maior porção populacional einclui, entre outros, os municípios de Brasília, Goiânia, A parecida de Goiânia, A nápolis e Campo Grande. A o observar os dados referentes às áreas rural e urbana, constata-se que, nesses municípios, a população rural apresentou um declínio entre 1970 e 1991. De outro lado, a população urbana aumentou no mesmo período. 
A zona de expansão teve um crescimento populacional de 1970 a 1991, em consequêencia da rápida ampliação da agricultura e do grande incremento das cidades-satélites de B rasília. A oferta de empregos do setor de serviços dessas cidades é a principal explicação do crescimento dessa área no período analisado. Já o pequeno crescimento dos trabalhadores da agricultura pouco efeito teve no incremento populacional experimentado pela zona de expansão.

A zona de frontei ra deveu seu crescimento populacional, principalmente, ao grande número de trabal hadores rurais que se desl ocaram a esse território entre 1970 e 1991 . Segundo os autores, o principal município dessa área é Cuiabá. Por fim, a zona residual apresentou baixo crescimento médio anual da população, de 1970 a 1991, configurando uma área de baixo dinamismo econômico e demográfico.

D ois aspectos são lembrados por M ueller, Torres \& M artine (1992) como característicos da ocupação do Centro-O este. Primeiramente, percebe-se um aumento no preço das terras, ocasionado por efeitos especulativos, inflação instável, políticas de incentivo rural e programas de incentivo ao cultivo de determinados produtos. 0 aumento de preço estimulou a incorporação de regiões de fronteira, não com o intuito de produção agropecuária, mas pela motivação de ganhos com especulação fundiária. U ma segunda característica da ocupação desse território foi a modernização conservadora da agricultura, que começou no final da década de 1960. U ma conseqüência dessa modernização foi a falência de pequenos fazendeiros e 0 desemprego de trabalhadores rurais, que geraram fluxos migratórios, tanto para os grandes centros urbanos, como para regiões de agricultura de fronteira.

A partir dos estudos apresentados anteriormente, constata-se que houve uma mudança no padrão de migração no Centro-O este. Se, em um determinado momento, era predominante a migração para áreas de fronteira, em um momento mais recente a migração em direção às grandes cidades da região passa a se sobressair. No entanto, não é correto fazer um corte cronológico estabelecendo diferenças entre os períodos analisados, como se um tipo de migração anulasse o outro. É importante realizar diferenciações dos tipos de migração no decorrer do tempo, mas é preciso salientar que essas modalidades de migração ocorreram concomitantemente, em diferentes épocas, e a prevalência de um uma é mais visível em um determinado período do que em outro.

Segundo levantamento de Oliveira (1997), os anos 60 apresentaram as maiores taxas de crescimento do Centro-Oeste, considerando-se o período de 1940 a 1996. Isso ocorreu em decorrência da fundação de B rasília, da abertura de estradas em direção à nova capital federal e da realização de políticas de incentivo à ocupação fundiária dessa região. $\mathrm{N}$ a década de 1970, houve um arrefecimento do fluxo migratório em direção ao $M$ ato Grosso do Sul e a Goiás, em conseqüência da intensa concentração fundiária, característica dessa ocupação de fronteira. A té então, $0 \mathrm{M}$ ato $\mathrm{G}$ rosso não havia recebido grandes fluxos migratórios, se comparados aos demais estados do Centro-O este. A partir da década de 1970 até fins da década 1980, os fluxos populacionais dirigiram-se primordialmente para esse estado. Porém, já nos anos 90 , a migração em direção ao $M$ ato $G$ rosso também teve seu volume reduzido, em decorrência do mesmo processo de concentração fundiária dos demais estados da região, o que impossibilitou a exploração da terra por pequenos proprietários.

Os dados da Contagem $\mathrm{Nacional}$ de População de 1996 indicaram um esgotamento da migração para ocupação fundiária. Os atuais fluxos em direção a Goiás e ao Distrito Federal tomaram uma nova feição.

[...] os migrantes de outras regiões, especialmente os nordestinos, que durante a década de 90 se fixaram nos municípios goianos do entorno de Brasília e nos novos bairros periféricos do Distrito Federal, não mais vieram em busca de terras ou oportunidades em áreas pioneiras, mas, sim, buscaram condições de trabalho, moradia e acesso aos serviços públicos em áreas fortemente urbanizadas e prestadoras de serviços, tais como a capital federal e Goiânia. (Oliveira, 1997)

A o aval iar os movimentos migratórios no Centro-O este ampliado (Goiás, M ato Grosso, $M$ ato $G$ rosso do Sul, Distrito Federal, Rondônia 
e Tocantins), e sem desconsiderar que ainda havia um processo de ocupação de áreas de fronteira nos anos 90, Cunha (2001) nota que o novo padrão de redistribuição populacional da região é caracterizado pelo crescimento e pela consolidação dos grandes centros urbanos, principalmente Goiânia e Distrito Federal. Segundo esse estudo, a microrregião de Goiânia é a principal área de atração dos migrantes interestaduais e intra-estaduais de Goiás. A lém disso, o Entorno de Brasília é a microrregião que mais absorve o fluxo migratório proveniente do Distrito Federal. Considerando os volumes de migração interestadual e intra-estadual, 0 autor afirma que

0 quadro demográfico recente de Goiás é 0 rápido crescimento de sua população urbana e progressiva redução do contingente rural. [...] A companhando a dinâmica demográfica, os movimentos migratórios no Estado de Goiás também se intensificam muito na área urbana em detrimento dos fluxos para o rural. No período $91 / 96$ mais de $90 \%$ dos migrantes em Goiás dirige-se para o urbano [...]; as microrregiões mais visadas pelos migrantes urbanos neste mesmo período foram: G oiânia, Entorno de Brasília, M eia Ponte e A nápolis. (Cunha, 2001)

Observa-se que as microrregiões de Goiânia e Entorno de B rasília, a partir da década de 1980 , constituíram as regiões que mais atraíram contingentes populacionais entre todas as microrregiões de Goiás. A gora, a migração dirige-se aos centros urbanos e não mais às regiões de fronteira agrícola. Surgem, então, questões importantes que devem ser melhor exploradas e explicadas. Quais são as origens desses novos migrantes com destino a Goiás e ao Distrito Federal? São eles oriundos do próprio estado ou vêm de outras unidades da federação? Há uma predominância de sexo, faixa etária ou renda desses migrantes?

3 Perfil da migração em Goiás e Distrito Federal, com base nos Censos de 1980 e 1991

Com o objetivo de compreender o processo migratório recente para G oiás e D istrito F ederal e de posse dos microdados dos Censos Demográficos de 1980 e 1991, foram calculadas as probabilidades de migração, referentes aos indivíduos que se deslocaram de diferentes regiões do país com destino a essas regiões. Foi realizada uma divisão do território nacional em nove áreas: microrregião de G oiânia, microrregião do Entorno de Brasília, as outras 16 microrregiões de Goiás, Distrito Federal, $M$ ato $G$ rosso e M ato G rosso do Sul, N orte, N ordeste, Sudeste e Sul. As 16 microrregiões de Goiás agrupadas são: São M iguel do A raguaia, Rio Vermelho, A ragarças, Porangatu, Chapada dos Veadeiros, Ceres, A nápolis, I porá, A nicuns, V ão do Paraná, Sudoeste de Goiás, Vale do Rio dos Bois, M eia Ponte, Pires do Rio, Catalão e Quirinópolis.

Houve uma análise dos níveis e padrões das funções de migração estimadas, referentes aos deslocamentos populacionais rumo à microrregião de Goiânia, à microrregião do Entorno de Brasília, ao Distrito Federal e ao conjunto das outras 16 microrregiões de Goiás, nos qüinqüênios 1975-1979 e 1986-1990. A lém disso, foram realizadas análises do perfil econômico e educacional dos migrantes dessas regiões, nos dois períodos, seguidas de uma classificação dos tipos de movimentos migratórios em 1986-1990.

As análises das funções de migração dos períodos 1975-1979 e 1986-1990 auxiliaram a percepção de tendências gerais da migração em Goiás e no Distrito Federal. Quanto aos diferenciais de nível entre as probabilidades masculinas e femininas, observou-se que, para as grandes metrópoles anal isadas (microrregião de Goiânia e Distrito Federal), a migração de mulheres foi mais acentuada. Enquanto isso, a migração para o grupo de 16 microrregiões de Goiás foi marcada por um maior nível de movimentos masculinos.

Com relação ao nível da migração intraestadual, a principal região de destino dos migrantes da microrregião de G oiânia é o grupo de 16 microrregiões de Goiás, e o nível da migração para o Distrito Federal não é alto. Os emigrantes da capital nacional têm como principal destino a microrregião do Entorno de Brasília. Por sua vez, as probabilidades do Entorno de Brasília indicam que essa área 
apresenta tendências emigratórias declinantes, e o Distrito Federal e o grupo de 16 microrregiões são os principais locais de destino dos migrantes.

Em nível interestadual, as migrações com destino às 16 microrregiões de Goiás foram principalmente originárias do $M$ ato Grosso e $\mathrm{M}$ ato $\mathrm{G}$ rosso do Sul, e a proximidade territorial talvez seja uma explicação para a ocorrência dessa migração. 0 N orte apresentou probabilidades de emigração total muito reduzidas para Goiás e Distrito Federal, e os fluxos mais expressivos dirigiram-se à microrregião de Goiânia e às outras 16 microrregiões de G oiás. O N ordeste, Sudeste e Sul apresentaram níveis de emigração maiores em direção ao Distrito Federal, mesmo com uma queda muito acentuada das probabilidades em 1986-1990.

A capacidade de atração migratória do Distrito Federal diminuiu consideravel mente do período 1975-1979 para 1986-1990. Enquanto isso, as probabilidades específicas de emigração em direção à microrregião do Entorno de B rasília cresceram vertiginosamente, indicando que ela exerce uma atração cada vez maior para seus municípios, em comparação à absorção migratória das outras microrregiões goianas e da capital nacional. A utilização de somente dois censos na análise das probabilidades de emigração dificulta a delimitação de tendências futuras da migração. Porém, fica evidente que trabalhos de projeções devem levar em consideração o baixo poder de retenção da capital federal, por um lado, e o crescimento da absorção migratória da microrregião do Entorno de B rasília, por outro.

Quanto aos padrões das funções de migração, estes foram classificados pela presença ou ausência de migração familiar e pelo baixo, médio ou al to grau de concentração das probabilidades proporcionais em torno das idades de maior emigração. As funções de migração com destino à microrregião de Goiânia e ao Entorno de Brasília caracterizaram-se por altas probabilidades nas primeiras idades, evidenciando um padrão familiar da migração. Isso reforça as argumentações de Salim (1992) de que migrantes que haviam se direcionado para regiões de fronteira do Centro-O este e do $\mathrm{N}$ orte, redirecionaram-se para centros urbanos de Goiás. Ainda em relação ao Entorno de B rasília, as probabilidades de emigração provenientes do Distrito Federal evidenciam uma forte migração familiar, reforçando as argumentações de Cunha (2001) de que famílias que moravam em áreas mais valorizadas do Distrito Federal estão migrando para municípios do Entorno de Brasília, que seriam a periferia da capital nacional.

As funções de migração com destino ao Distrito Federal apresentam baixas probabilidades nas primeiras idades, o que caracteriza um padrão não-familiar de migração desde 0 período 1975-1979. Em 1986-1990, observa-se uma al ta concentração de migrantes entre $10 \mathrm{e}$ 35 anos, o que indica uma forte migração de pessoas em idades economicamente ativas.

As probabilidades específicas de emigração proporcionais do grupo de 16 microrregiões de Goiás apresentaram altos valores nas primeiras idades, desde 1975-1979, o que permite pensar que áreas de fronteira, diferentemente de centros urbanos, apresentam grande migração familiar para seus territórios. 0 grau de concentração em torno das maiores probabilidades foi baixo ou médio, o que mostra a tendência dessas áreas de não possuírem forte poder de atração migratória de pessoas em idades economicamente ativas, as quais estão se mudando primordialmente para os centros urbanos de G oiás e Distrito F ederal.

As análises de caracterização mostraram que os migrantes da microrregião de Goiânia e do Distrito Federal têm menos chances de ter trabal hado nos últimos 12 meses e de possuir cartei ra de trabalho assinada do que aqueles que não migraram. Isso pode ser conseqüência da queda da disponibilidade de emprego nessas áreas, que causa perda da capacidade de atração migratória por essas regiões. Quanto ao Entorno de Brasília, os migrantes do Distrito Federal exibem altas probabilidades de terem trabalhado e de possuir carteira de trabalho assinada, se comparados aos que não migraram. Isso indica que essa microrregião pode estar captando trabalhadores da capital nacional, e serve como um indicativo dos motivos do aumento dos níveis das probabilidades de emigração total do Distrito Federal para o Entorno de Brasília. 
A classificação dos migrantes em faixas de salários mínimos permitiu constatar que os indivíduos que se destinaram à microrregião de Goiânia, provenientes da microrregião do Entorno de Brasília, de 16 microrregiões de Goiás, do N orte e do N ordeste, percebem piores remunerações do que aqueles oriundos do Distrito Federal, do Sudeste e do Sul. Quanto ao Entorno de Brasília, os não-migrantes e os migrantes provenientes de 16 microrregiões de Goiás, do N ordeste e do Sudeste concentramse em baixas faixas de salários mínimos. Os migrantes nordestinos, mesmo tendo funções de migração com a mais alta concentração entre idades economicamente ativas, em 1986-1990, são caracterizados pela baixa remuneração.

Os migrantes que se destinaram ao D istrito Federal apresentaram baixo rendimento quando provenientes do Entorno de Brasília, de 16 microrregiões de Goiás, do N orte e do Nordeste. Essas informações, aliadas àquel as das funções de migração, indicam expressiva migração de pessoas de baixa renda para a capital federal, em idades economicamente ativas. Os migrantes provenientes do Sul apresentaram altas porcentagens nas faixas superiores de rendimentos. Os migrantes que se deslocaram para o grupo de 16 microrregiões de G oiás concentraram-se nas faixas mais baixas de rendimentos, o que pode ser conseqüência de um menor nível de qualidade de vida nessas microrregiões ou do fato de os migrantes apresentarem probabilidades de emigração com baixa concentração em idades economicamente ativas, o que aumenta a participação da renda de pessoas mais velhas, que geralmente são mais baixas.

Os dados sobre escolaridade mostraram que, para a microrregião de G oiânia, somente os migrantes provenientes do Sudeste e do Sul apresentaram alto nível de anos de estudo. Os percentuais de migrantes analfabetos foram al tos para os originários do Entorno de B rasília, 16 microrregiões de Goiás e N ordeste. Para os migrantes que se direcionaram ao Entorno de B rasília, houve uma grande concentração na faixa de analfabetos para os não-migrantes e migrantes provenientes da microrregião de Goiânia, Distrito Federal, 16 microrregiões de Goiás, N orte, N ordeste e Sudeste. Ressaltamse, assim, as argumentações de Cunha (2001) de que migrantes de menor nível socioeconômico estão se direcionando para essa microrregião, já que o alto custo de vida do Distrito Federal acaba expulsando esses indivíduos. Para o Distrito Federal, são reservados os melhores níveis de escolaridade. Isso pode estar indicando uma migração de pessoas com melhores níveis de escolaridade ou de indivíduos que buscam ascender em anos de estudo no local de destino, visto que não teriam essas condições na região de origem. No conjunto de 16 microrregiões de Goiás, percebem-se altas porcentagens de analfabetos não-migrantes e migrantes provenientes das várias regiões de origem.

Com base nas análises dos tipos de movimentos migratórios, constatou-se que a maioria dos migrantes efetuou apenas um deslocamento no qüinqüênio 1986-1990. Na microrregião de Goiânia, os migrantes retornados plenos são uma parcela considerável entre os que se destinaram a essa área. Isso é evidente para os migrantes vindos do $M$ ato Grosso e $M$ ato G rosso do Sul e do Distrito Federal. Parte desses migrantes podem ser estudantes que se mudaram temporariamente da microrregião. Os migrantes retornados plenos são ainda uma considerável parcela daqueles que se deslocaram para o grupo de 16 microrregiões de Goiás, o que pode indicar que a forte emigração dessa região acabou ocasionando o retorno de muitas pessoas no final do qüinqüênio 19861990.

No caso do Entorno de Brasília, algumas porcentagens de migrantes retornados plenos parecem indicar uma emigração temporária dessa microrregião para regiões territorialmente próximas, com o retorno dos migrantes no final do período. Quanto aos migrantes de passagem, percebe-se a importância dessa microrregião como região de absorção final de migrações de caráter familiar, provenientes de centros urbanos, com custo de vida mais elevado. Famílias de baixa renda do Sudeste e Distrito Federal migraram para regiões próximas ao Entorno de Brasília, durante o período 1986-1990, chegando a essa microrregião no final do qüinqüênio. Percebe-se ainda uma grande quantidade de migrantes de passagem pelo Distrito F ederal, provenientes do N ordeste, o que enfatiza o processo de emigração de pessoas 
de baixa renda da capital nacional para o Entorno de Brasília.

Com relação aos migrantes que se direcionaram para o Distrito Federal, há uma grande porcentagem de retornados plenos provenientes do Entorno de Brasília, sugerindo que essa microrregião não está sendo capaz de reter os migrantes em seu território, mesmo apresentando grande capacidade de atração migratória. No que se refere aos migrantes de passagem, 0 Distrito Federal apresenta tendência de queda na absorção de famílias migrantes, mas ainda há casos desses migrantes vindos do Sudeste na data fixa, que migraram para outras regiões durante o período 1986-1990, e depois se deslocaram para a capital nacional.

Futuros estudos poderão estimar probabilidades específicas de emigração não só para Goiás e Distrito Federal, como também para todo o território brasileiro. Isso permitirá uma comparação com os resultados aqui obtidos, assim como possibilitará o desenvolvimento de técnicas diretas e indiretas de migração com 0 objetivo de superar eventuais deficiências dos dados disponíveis.

\footnotetext{
Abstract: This article presents research about migratory movements in Goiás and Distrito Federal, Brazil. I synthesizes a picture of larger population attraction areas in the Centro-O este, Goiânia micro-regions, and Distrito F ederal's E ntorno. Initially, it indicates a migratory redriving to the region in the $70^{\prime} \mathrm{s}$, originated from capital develgpment in agriaulture, with agriculture mechanization and alteration of social relations of production. Such changes in the previous situation of population absonption, gives place to a larger worker's flow towards the cities. The final part of the article brings a migration profile of these regions, based on literature categories for migration flows and territory redefinition both induced by agriarlture modemization. Also, the authors utilize techniques of migration analyses and compare trends of the two fundamental areas with data of 16 G oiás micro-regions.
}

K ey-words: migration; Região C entro-0 este; modemization.

\section{Referências}

AGRESTI, Alan. An introduction to categorical data analysis. New Y ork: J ohn Wiley \& Sons, 1996.

ALLISON, Paul D. Logistic regression: using the SA S system. Cary, North Carolina, USA: SA S Institute Inc., 2000.
BA DANHAN, M arco A ntônio. A democratização da capital federal. B rasília: partidos e el eições (1985 a 1994). 1995. Dissertação (M estrado em Ciência Política) - Departamento de Ciência Política, Universidade de B rasília.

BELTRÃ O, Kaizô Iwakami; HEN RIQUES, M aria Helena Fernandes da T. M odelagem da migração líquida rural-urbana no B rasil: décadas de 1960/1970 e 1970/1980. Previdência em D ados, Rio deJ aneiro, v. 2, n. 3, p. 23-36, jul./set. 1987.

BORGES, B arsanufo Gomides. G oiás nos quadros da economia nacional: 1930-1960. Goiânia: Editora daUFG, 2000.

CA IAD O, M aria Célia S. Estrutura urbana e mobilidade intra-regional: a região do Entorno de Brasília. In: ENCONTRO NA CIONAL DE ESTUDOS POPULACIONAIS, 12, 2000, Caxambu. Anais... Belo H orizonte: A bep, 2000. 1 CD-ROM. Windows 95/98.

CA RVA L HO, J osé A Iberto M agno de. Estimativas indiretas e dados sobre migrações: uma avaliação conceitual e metodológica das informações censitárias recentes. Revista Brasileira de Estudos de População, Campinas, v. 2, n. 1, p. 31-73, jan./jun. 1985.

M igrações internas: mensuração direta e indireta. In: ENCONTRO NACIONAL DE ESTUDOS POPULACIONAIS, 2, 1980, Á guas de São Pedro. Anais... B elo Horizonte: A bep, 1981. v. 1, p. 533-577.

CA RVA L HO, J oséA lberto M agno de; M A CHADO, Cláudio Caetano. Quesitos sobre migrações no Censo Demográfico de 1991. Revista Brasileira de Estudos de População, Campinas, v. 9, n. 1, p. 2234, jan./jul. 1992.

CA RVA LHO, J osé A lberto M agno de; RIGOTTI, J osé I rineu R angel. Os dados censitários brasileiros sobre migrações internas: algumas sugestões para análise. Revista Brasileira de Estudos de População, B rasília, v. 2, n. 15, p. 7-18, jul./dez. 1998.

CA RVA LHO, J osé A lberto M agno de; SAWYER, Diana Oya; RODRIGUES, Roberto do Nascimento. Introdução a alguns conceitos básicos e medidas em demografia. 2.ed. São Paulo: A bep, 1998.

CHA UL, Nasr Fayad. Caminhos de Goiás: da construção da decadência aos limites da modernidade. Goiânia: Editora da U FG, 1997.

CUNHA, J osé M arcos Pinto da (Coord.). Redistribuição da população e meio ambiente: São Paulo e Centro-O este. Campinas: Nepo/U nicamp, 2001. [Relatório final]

FA USTO, Boris. H istória do Brasil. 2.ed. São Paulo: Editora da USP, 1995. 
IBGE. Censo demografico 1980: microdados. Rio de Janeiro: IBGE, 1980. [Disponível em meio magnético]

Censo demografico 1991: microdados. Rio de J aneiro: IB GE, 1991. [Disponível em meio magnético] J ANNUZZI, Paulo de M artino. Interpretação e modelagem de perfis etários da migração: uma contribuição a partir da análise de taxas migratórias específicas por motivos e específicas por acompanhantes da mudança. In: EN CONTRO NA CIONAL SOBRE MIGRAÇÃ O, 1, 1997, Curitiba. Anais... Curitiba: I pardes/Fnuap, 1998. p. 229-271.

MACHADO, Cláudio Caetano. Projeções multirregionais de população: o caso brasileiro (19802020). 1993. Tese (Doutorado em Demografia) Centro de Desenvolvimento e Planejamento Regional, U niversidade Federal de M inas G erais, 1993.

M UELLER, Charles; TORRES, Haroldo; M A RTINE, George. An analysis of forest margins and savanna agrosystems in Brazil. B rasília: ISPN, 1992.

PA STORE, J osé. Brasília: a cidade e o homem. São Paulo: Companhia Editora Nacional, 1969.

RIBEIRO, JoséTeixeira Lopes; CA RVA LHO, J osé A lberto M agno de; W ON G, Laura Rodríguez. Efeitos demográficos da migração de retorno: uma proposta metodológica. In: ENCONTRO NACIONAL DE ESTUDOS POPULA CIONAIS, 10, 1996, Caxambu. Anais... B elo Horizonte: A bep, 1996. v. 2, p. 955-972.

. M igração de retorno: algumas possibilidades de mensuração. In: ENCONTRO NACIONAL DE ESTUDOS POPULA CIONAIS, 10, 1996, Caxambu. Anais... Belo Horizonte: A bep, 1996. v. 2. p. 9731002.

ROGERS, A.; CASTRO, J. L. Model migration schedules. Laxenburg, A ustria: International Institute for A pplied Systems A nalysis, 1981.

SALIM, Celso A morim. Estrutura agrária e dinâmica migratória na Região Centro- 0 este, 1970-80: análise do êxodo rural e da mobilidade da força de trabal ho no contexto de industrialização da agricultura e da fronteira urbanizada. 1992. Tese (D outorado em Demografia) - Centro de Desenvolvimento e Planejamento Regional, U niversidade Federal de M inas Gerais, 1992.

UNITED NATIONS. Preparing migration data for subnational population projections. New York: U nited N ations Publication, 1992.

Recebido em Setembro de 2003 A provado em feVereiro de 2004 